\title{
Focus Honoring R. Graham Cooks, Recipient of the 2006 ASMS Award for Distinguished Contribution in Mass Spectrometry
}

$\mathrm{T}$ The recipient of the 2006 ASMS Award for Distinguished Contribution in Mass Spectrometry is R. Graham Cooks, the Henry B. Hass Distinguished Professor of Chemistry at Purdue University. The award is for Graham's work in the development of the "kinetic method." The use of the competitive dissociation of proton-bound species to determine proton affinities was first demonstrated 30 years ago (Cooks, R. G.; Kruger, T. L. Intrinsic Basicity Determination Using Metastable Ions. J. Am. Chem. Soc. 1977, 99, 1279). Because the technique is based on the kinetics of dissociation rather than on establishing equilibrium between two species, it dramatically expands the range of compounds whose gas-phase thermochemical properties can be determined. The initial work using the kinetic method involved determination of proton affinities, but in the subsequent decades, it has been used to determine a number of other thermochemical properties of gas-phase ions: basicities, acidities, electron affinities, ionization energies, atomic (e.g., $\mathrm{Na}^{+}$) and polyatomic (e.g., $\mathrm{NO}^{+}$) ion affinities, and entropy changes upon protonation. Other chemical information that can be derived from the kinetic method includes estimates of steric sizes of substituents and distinguishing stereoisomers from one another.

The kinetic method is only one of a number of areas in which Graham's laboratory has made seminal contributions in the field of mass spectrometry. The kinetic method is a tandem mass spectrometry (MS/MS) experiment and one of the developments from the early years of the technique. Concurrent with the early work on the kinetic method was pioneering work in the development of analytical MS/MS for mixture analysis. Graham is also certainly well known for his contributions to the development of mass spectrometry instrumentation. The first hybrid tandem mass spectrometer for analytical applications of MS/MS was constructed in his laboratory around the same time that the kinetic method was being developed. This hybrid instrument was subsequently used for the development of the surface-induced dissociation (SID) technique. Related to SID, the modification of surfaces by the "soft landing" of ions is another area of research where Graham has been a pioneer. While most of the published work on soft landing has occurred in the past decade, the initial experiments were again performed in the time period when the kinetic method was being developed. (This is an example of how a good idea can take decades to

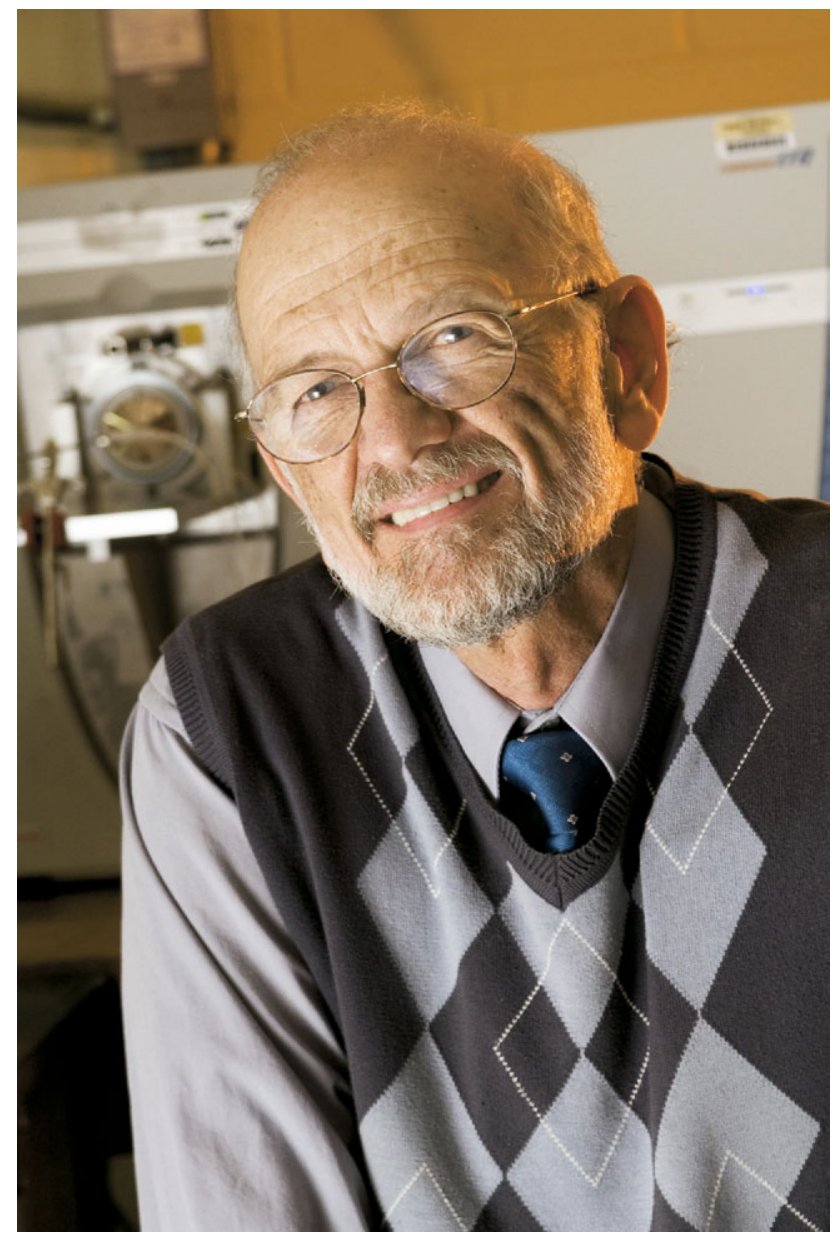

come to fruition - a time frame over which most people would have given up.)

Graham is also well known for his contributions to the development of quadrupole ion-trap mass spectrometry, with many experimental and theoretical advancements coming from his laboratory. The ion-trap work has evolved into an extensive research program to develop miniature mass spectrometers. More recently, the technique of desorption electrospray ionization (DESI) resulted from the efforts of Graham and his research group.

Obviously, all this work $(800+$ publications $)$ has involved a large number of students, postdoctoral associates, and visiting scientists. Currently there are 249 past and present group members listed on the Cooks' group website (http://aston.chem.purdue.edu/ 
members/alumni).đhis@arge@umber@s@@estament@o the welcoming nature of Graham and his group. I have never heard him say "no" to anyone who wanted to spend time in his laboratory.

For this Focus issue honoring Graham's award, we decided to invite former colleagues to contribute rather than having a theme based on the award topic. Given the large number of people that group encompasses and the finite limit of journal space, the invitation list was limited to former students from the "early" years (almost exclusively the 1980s). There are seven articles from eight former students. While there is not a specific scientific theme, the influence of the instrumentation emphasis of Graham's research is apparent. Three articles are "Accounts and Perspectives," which review topics in mass spectrometry. These articles are "Hybrid Mass Spectrometers for Tandem Mass Spectrometry" by Glish (1980) and Burinsky (1982), "Evolution of Instrumentation for the Study of Gas-Phase Ion/Ion Chemistry via Mass Spectrometry" by McLuckey (1982) and colleagues, and "Surface-Induced Dissociation of Small Molecules, Peptides, and Noncovalent Protein Complexes" by Wysocki (1987) and colleagues. The other four contributions are research articles spanning a range of topics: "Evaluation of Metal-Mediated DNA Binding of Benzoxazole Ligands by Electrospray Ionization Mass Spectrometry" by Brodbelt (1988) and colleagues, "The Analysis of Polystyrene and Polystyrene Aggregates into the Mega Dalton Mass Range by
Cryodetection MALDI TOF MS" by Bier (1988) and colleagues, "Fragmentation of Multiply Charged Intact Protein Ions Using MALDI TOF-TOF Mass Spectrometry" by Schey (1989) and colleagues, and "Automated In-Line Gel Filtration for Native State Mass Spectrometry" by Williams (1992) and colleagues.

Organizing this Focus issue is my last official duty as an associate editor of the journal, and it was an honor and privilege to do this for Graham. I do apologize to the many former and current colleagues who spent time in Graham's laboratory and would have liked to have contributed to this issue honoring him but were not invited to do so. Maybe you can take comfort in the fact that you do not fall into the "early" category, which some people tell me is now synonymous with "old." However, one cannot feel old if you let Graham's spirit and energy rub off on you. One of my favorite quotes, by George William Curtis, is "Age is a matter of feeling, not years." On the basis of that philosophy, I do not believe that Graham has aged a day since I first met him in the fall of 1976. I cannot imagine a better mentor and role model, and I am sure everyone joins me and the authors of this Focus issue in congratulating Graham on a well-deserved award.

Gary Glish

Department of Chemistry, University of North Carolina Chapel Hill, North Carolina, USA 